\title{
A Model for Hypogalactia Treatment Using Electrical Acupoint to Increase Breast Milk Volume and Improve Prolactin Content
}

\author{
Sheyla Najwatul Maula ${ }^{1, *}$, Melyana Nurul Widyawati ${ }^{1}$, and Suryono Suryono ${ }^{2}$ \\ ${ }^{1}$ Post Graduate Applied Science Midwifery Program, Poltekkes Kemenkes Semarang - Indonesia \\ ${ }^{2}$ Physics Department, Faculty of Mathematics and Natural Sciences, Universitas Diponegoro, Semarang - Indonesia
}

\begin{abstract}
Hypogalactia is one of the problems for breastfeeding mothers that accounts for $63 \%$. Nowadays, efforts have been done to prevent hypogalactia pharmacologically. However, this approach often comes with side effects for the mothers. This research proposes the implementation of non-pharmacological electrical acupoint method via activation of neurological, bio-mechanical, and psychological systems. It is aimed at proving the method's efficacy in improving breast milk volume and prolactin level. The model of electrical acupoint is carried out at 0.5 watt frequency of scale 3 for 10 minutes at acupoints $\mathrm{SI}_{1}, \mathrm{ST}_{36}$ and $\mathrm{SP}_{6}$. Paired t-test statistical test was then conducted to differentiate the effects of electrical acupoint treatment on breastfeeding mothers. Results show significant differences $(\mathrm{p}<0.05)$ after implementation of electrical acupoint. This significant difference is proven from the unpaired t-test which indicated different results of pre-and post-treatment. This means that electrical acupoint improves breast milk volume by an average of $70.915 \mathrm{~mL}$ and prolactin level by around $313.47 \mathrm{ng} / \mathrm{Ml}$. It can then be inferred that the use of electrical acupoint readily handles the problem of hypogalactia.
\end{abstract}

Keywords: Electrical Acupoint; Hypogalactia; breast milk volume; and prolactin level.

\section{INTRODUCTION}

Breastfeeding is a post-natal critical period. Any delay in administering breastfeeding may cause problems in lactation processes correlated to the conditions of anxiety that is detrimental to both mothers and their babies[1]. Breastfeeding problems such as hypogalactia is due to a late phase of lactogenesisII caused by stress, congenital dysplasia, dietary issues, and lack of zinc[2]. Hypogalactia is marks by minimum breast milk production that requires intervention on the meridian point with stimuli.

Breast milk production with the help of electric pump without any stimuli results in low satisfaction level and effectiveness, along with insignificant increase in breast milk volume[3]. Pharmacological methods have been attempted to deal with hypogalactia like in the use of metoclopramide, carbamazepine and domperidone that have proven to be effective. However, their use often come with side effect that non-pharmacological methods are sought after as probable alternatives to minimize side effects $[4,5]$.

On the other hand, traditional Chinese medication views hypogalactia as due to the presence of qi blood cloths. Electrical acupoint is one of the latest technologies in health. This technology is not yet widely used in stimulating breast milk production. Acupoint is implemented based on the principle of activating specific points in the meridian that in turn serve as stimuli in the body to smoothen the flow of $q i$ and blood, and hence, improve breast milk production[6]. Body meridian itself is thought of as oscillating systems that interact with one another. When stimuli are positioned in the meridian line, they naturally activate the body system mechanism[7].

Electrotherapy using electrical acupoint can effectively increase the volume of breast milk compared to the other methods available. This is possible as the technique used in acupoint stimuli is flowing low frequency electricity along the meridian line directly connected to targeted organs and the hypothalamus in the brain. This low frequency electricity improves body response as there is a balancing of $q i$ as the meridian line, and hence, harmony among body organs is activated[8].

Bio-chemistry mechanism stimuli are injected via electrical acupoint into meridian points and they have four times faster response with the help of activated impulses to the brain, especially the neuro-hormonal pituitary-adrenocortical axis complex. The feedback of this mechanism is relaxation response and lower cortisol production, which is one of the causes of hypogalactia. Relaxation is the result of physiological response of the body against acupoint stimuli, by improving endorphin and serotonin transmittance to the brain and the other organs via the nerves and the meridian[9].

\footnotetext{
*Corresponding author: sheylanajwa@gmail.com
} 
Response against low frequency electrical stimuli on acupoint points not only affects the body's hormonal mechanism, but also the nearest local tissues around the acupoint, along the meridian. Those stimuli trigger the secretion of neurotransmitters and opioids that release neuropeptide hormones to serve as stimuli for the hypothalamus and the pituitary gland. The feedback of this mechanism maintains the consistence of nitrite oxide (NO) and cyclic guanosine monophosphate (cGMP) in the local mechanism and the hormonal mechanism, with increase prolactin secretion for improvement of breast milk secretion[7]. The human body has an inherent ability to naturally maximize physical processes without requiring the use of drugs which otherwise come with side effects. In low carbon building, the use of electronic instrumentation can facilitate performance so as to increase productivity in the industrial world $[10,11]$.

\section{METHOD}

This is a truly experimental research using randomized controlled trials (RCTs) design of phase III clinical test. It was carried out in 6 working areas of Puskesmas (community health center) Semarang City in Indonesia. Two research groups were involved, i. e. intervention and control. The intervention group consists of breastfeeding mothers undergoing electrical acupoint treatment and massage therapy, while the control comprises breastfeeding mothers undergoing only massage therapy. Both group members were measured for their breast milk volume, and their prolactin content.

Population of the 6 working areas consists of 269 people. During the research, 229 respondents were in the exclusion criterion. Other than that, 4 respondents had to be dropped out. This means that there were 36 subjects meet the inclusion criteria of this research. They then underwent intervention using electrical acupoint and massage therapy according to the manual book for 2 weeks.

This research applied hypogalactia treatment using electrical acupoint involving acupoint points $\mathrm{ST}_{36}, \mathrm{SI}_{1}$ and $\mathrm{SP}_{6}$. Electrotherapyacupoint $\left(\mathrm{SI}_{1}\right)$ does not only increase breast milk production, but it also improves prolactin content. Low frequency electrical stimuli (0.5 $\mathrm{W})$ in electrical acupoint are applied on the skin surface using stainless steel electrodes on scale 3 for 10 seconds for each acupoint.

Prolactin content is analyzed using laboratory blood serum sample for both pre and post tests. Other than that, breast milk volume is evaluated by pumping for both pre and post tests. Results of this pre and post tests show improvement in terms of more breast milk volume, and better prolactin content. Therefore, it can be concluded that Ho is rejected, whereas Ha is accepted. Those data indicate that the effect of implementing electrical acupoint to increase breast milk volume, and gain proper prolactin content is significant.

Data of this research are compared for pre and post test values using mean difference in order to show the discrepancies between the two. Results show that the mean difference for breast milk volume and prolactin content for the intervention group is higher, compared to that of the control group.

Interpretations from data of breast milk volume and prolactin content before and after the implementation of electrical acupoint show significant mean values with $p$ value $(>0.05)$.

\section{RESULT ANALYSES}

Univariate analysis was used to characterize research subjects in terms of age, educational level, employment, parity, and breastfeeding history. Results of that analysis reveal descriptions of frequency, mean, and standard deviation. Respondents' mean age is found to be homogeneous with $\mathrm{p}$ value $=0.508$. Univariate analysis test was also carried out for results of breast milk volume and prolactin content in order to analyze frequency distribution of each measurement.

Meanwhile, for bivariate analysis, statistical test was conducted prior to normality and homogeneity tests. Normality test employed skewness calculation. Dependent bivariate analysis then proceeded for normal data distribution using parametric testing (paired t-test), whereas abnormal data distribution made use of nonparametric testing (Wilcoxon test).

On the other hand, independent bivariate analysis proceeded for normal data distribution using parametric testing (unpaired t-test), while abnormal data distribution employed non-parametric testing (Mann-Whitney test). Homogeneity tests for both prior to and after treatment reveal that each group is homogeneous ( $p>0$. 05). Results of bivariate analysis have been analyzed for measurements of breast milk volume and prolactin content. Further analysis then compared results, both among variables and among groups.

Analysis for breast milk volume both prior to and after treatment using electrical acupoint for intervention and control groups is depicted in Figure 1.

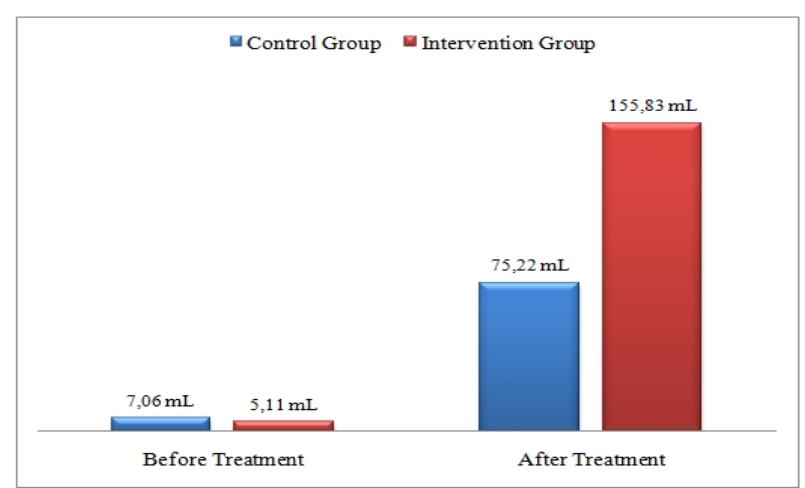

Figure 1. Frequency distribution of breast milk volume before and after electrical acupoint treatment.

It can be inferred from Figure 2 that for the intervention group, mean breast milk volume prior to treatment is $5.11 \mathrm{~mL}$, and it increases to $155.83 \mathrm{~mL}$ after treatment. In the meantime, the control group indicates 
mean breast milk volume of $7.06 \mathrm{~mL}$ prior to treatment. Therefore, mean breast milk volume after treatment increases to a mean of $75.22 \mathrm{~mL}$.

Lactation process itself is affected by complex hormonal mechanisms including reproduction hormones (estrogen, progesterone, placental lactogenic, prolactin, and oxytocin), as well as metabolic hormones (glucocorticoid, insulin, growth hormone, and thyroid). Reproduction hormones directly involves in lactation in mammary gland, while metabolic hormones indirectly influences lactation via endocrine and nutritional response to the breast glands. Producing and secreting breast milk requires balanced coordination among sensory, autonomous, and hormonal responses to stimulate the periphery nerves, central mechanism, and myoephitel cells[12].

Analysis for prolactin content both prior to and after treatment using electrical acupoint for intervention and control groups is depicted in Figure 2.

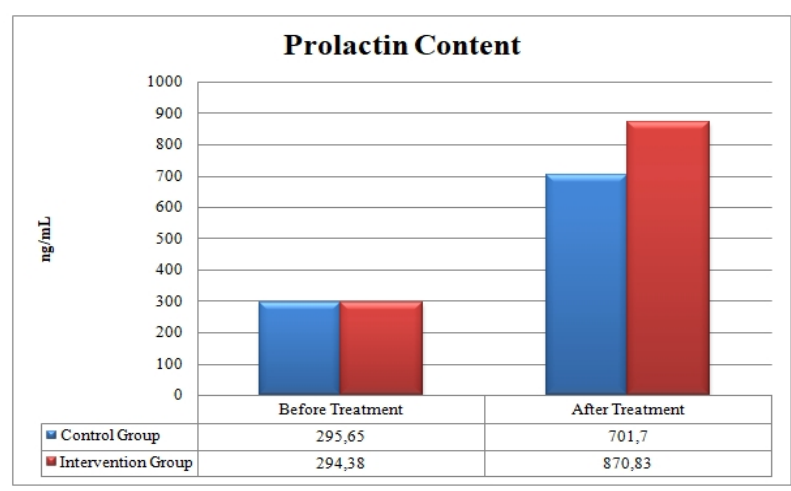

Figure 2. Frequency distribution of prolactin content before and after electrical acupoint treatment.

It can be interpreted from Figure 2 that both intervention and control group experience significant increases in prolactin content before and after treatment. Mean prolactin content for the intervention group prior to treatment was $294.38 \mathrm{ng} / \mathrm{mL}$, and was increased to 870 . $83 \mathrm{ng} / \mathrm{mL}$ after treatment. Meanwhile, the control group saw an increase from $295.65 \mathrm{ng} / \mathrm{mL}$ to $701.70 \mathrm{ng} / \mathrm{mL}$.

Early lactation stimulates more prolactin production that in turn affects breast milk production. Prolactin hormone produces breast milk by triggering contraction among myoephitel cells in the breast as a response to suction of the nipple, thanks to neurogenic reflexes sent to the hypothalamus via medulla spinalis[13]. Breastfeeding by providing stimuli via mu or kappa receptor increases prolactin secretion. These stimuli can be obtained from the use of electrical acupoint that triggers secretion of mu receptor that is associated with cGMP[14].

Results of analysis of difference in stress level, breast milk volume and prolactin content before and after electrical acupoint treatment are given in Table 1 .

Table 1. Differences in breast milk volume and prolactin content before and after treatment.

\begin{tabular}{ccccccc}
\hline No & Group & $\begin{array}{c}\text { Mean } \\
\text { Pre-test }\end{array}$ & $\begin{array}{c}\text { Mean } \\
\text { Post-test }\end{array}$ & $\begin{array}{c}\text { Mean } \\
\text { Diff }\end{array}$ & Unit & P value \\
\hline \multicolumn{6}{c}{ Intervention } \\
\hline
\end{tabular}

\begin{tabular}{|c|c|c|c|c|c|c|}
\hline & $\begin{array}{l}\text { a. Breast Milk } \\
\text { Volume }\end{array}$ & $\begin{array}{c}\text { 5. } 11 \pm 2 . \\
026\end{array}$ & $155.8 \pm 29.8$ & 150.72 & $\mathrm{~mL}$ & $0.000^{* *}$ \\
\hline \multirow[t]{3}{*}{1} & $\begin{array}{l}\text { b.Prolactin } \\
\text { Content }\end{array}$ & 294. $38 \pm 585$ & $\begin{array}{c}\text { 870. } 8 \pm 202 . \\
0\end{array}$ & 576.45 & $\mathrm{ng} / \mathrm{mL}$ & $0.000^{* *}$ \\
\hline & & & Control & & & \\
\hline & $\begin{array}{l}\text { a. Breast Milk } \\
\text { Volume }\end{array}$ & 7. $06 \pm 3,670$ & 75. $22 \pm 14.6$ & 68.16 & $\mathrm{~mL}$ & $0.000^{*}$ \\
\hline 2 & $\begin{array}{l}\text { b.Prolactin } \\
\text { Content }\end{array}$ & $\begin{array}{c}295.65 \pm \\
508.18\end{array}$ & $\begin{array}{l}701.70 \pm \\
141.43\end{array}$ & 406. 04 & $\mathrm{ng} / \mathrm{dL}$ & $0.000^{* *}$ \\
\hline
\end{tabular}

Based on Table 1, it can be concluded that both intervention and control groups experience significant increase in breast milk volume and prolactin content, prior to and after treatment with $\mathrm{p}=<0.05$. Hence, the effect of electrical acupoint treatment in increasing breast milk and improving prolactin content is significant. This conclusion is supported by results from mean difference evaluation for the intervention group which proves to have higher mean difference compared to the control group.

Results of analysis of differences in breast milk volume and prolactin content before and after electrical acupoint treatment are given in Table 2.

Table 2. Differences in breast milk volume and prolactin content before and after electrical acupoint treatment between the groups.

\begin{tabular}{|c|c|c|c|c|c|c|c|}
\hline \multirow{2}{*}{ Variable } & \multirow[t]{2}{*}{ Group } & \multirow{2}{*}{\multicolumn{2}{|c|}{$\begin{array}{c}\text { Before } \\
\text { Mean } \pm \text { SD }\end{array}$}} & \multirow{3}{*}{$\begin{array}{c}\text { After } \\
\text { Mean } \pm \text { SD }\end{array}$} & \multirow{2}{*}{$\begin{array}{l}\text { Mean } \\
\text { Diff. }\end{array}$} & \multicolumn{2}{|c|}{$P$ value } \\
\hline & & & & & & pre & post \\
\hline \multirow{2}{*}{$\begin{array}{l}\text { Breast } \\
\text { Milk } \\
\text { Volume }\end{array}$} & Intervention & $\begin{array}{l}5 . \\
026\end{array}$ & $11 \pm 2$ & & 97.61 & \multirow[t]{2}{*}{$\begin{array}{l}0 . \\
057^{* *}\end{array}$} & \multirow{2}{*}{0.} \\
\hline & Control & $\begin{array}{l}7 . \\
670\end{array}$ & $06 \pm 3$. & 75. $22 \pm 14.6$ & 44. 22 & & \\
\hline \multirow[t]{2}{*}{$\begin{array}{l}\text { Prolactin } \\
\text { Content }\end{array}$} & Intervention & $\begin{array}{l}294 . \\
38 \pm 5\end{array}$ & & $\begin{array}{ll}870 . & 8 \pm 202 . \\
09 & \end{array}$ & 359.79 & \multirow[t]{2}{*}{$\begin{array}{l}0 . \\
874^{* *}\end{array}$} & \multirow[t]{2}{*}{$\begin{array}{l}0 . \\
015^{*}\end{array}$} \\
\hline & Control & $\begin{array}{l}295 . \\
65 \pm 5\end{array}$ & & $\begin{array}{l}701 . \\
43\end{array}$ & 267. 15 & & \\
\hline
\end{tabular}

Based on Table 2, it can be concluded that breast milk volume before and after electrical acupoint treatment shows significant mean difference. This is proven with $p$ value of unpaired t-test at 0.057 before treatment $(>0$. $05)$, and 0.000 after treatment $(<0.05)$. Those values indicate changing results after treatment. Mean difference values also reveal greater margins for the intervention group, compared to the control group.

Meanwhile, for prolactin content, results show significant mean difference before and after treatment with electrical acupoint. This is proven with $p$ value of Mann-Whitney test at 0.874 before treatment $(>0.05)$ and 0 . 015 after treatment $(<0$. 05). Those values indicate changing results after treatment. Mean difference values also reveal greater margins for the intervention group, compared to the control group.

According to the meridian theory, stimulated points along the meridian line affects and triggers the functions of local tissues. Acupoint mediates the secretion of nitride oxide (NO) that is known to improve local condition and the circulation of cyclic monophosphate guanosine (cGMP). This process helps improve physical performance by suppressing molecules that cause blood cloths. Continuous application of pressure effectively improves relaxation, regional blood circulation, 
parasympathetic nerves activation, reduced tissue adhesion, and lower neuromuscular stimulus[15].

Nitride Oxide (NO) is one of the most important message carrying molecules, just like neurotransmitter is, with the mechanisms and functions widespread across the body. Secretion of NO an nNOS is consistently higher on acupoint points in the skin due to stimuli with low frequency electricity. Increased NO results from many sources including the NO-ergic neural system that is associated with the function of acupoint in terms of stimulation with low frequency electricity. Latest studies revealed that low frequency electricity stimuli do not only affect acupoint points but also along the meridian line of the body (around $1.0 \mathrm{~mm}$ ). Application of low frequency electricity results in neurovascular alteration in the whole body within tens of seconds, which is then followed by changes in secondary bio-chemistry that in turn triggers tertiary endocrine changes within a few days or weeks[16].

Neuropeptide plays an important role in the brain function mechanism. Neuropeptide is secreted from periphery electrical stimuli that are beneficial to human health. Concerning lactation, brain function is governed by the chemical mechanisms of neurotransmitter and neuropeptide. The very latest research involving laboratory mice show that electrical stimuli at certain frequencies applied to particular points in the body are capable of releasing neuropeptide and triggering physiological effects for healing processes. In that case, the electrical stimuli on the mice induce the releases of argininevasoperine and oxytocin into incubation media. Other than that, secretion of peptide opioid effectively reduces pain and eases secretion of breast milk. This means that neuropeptide can be modulated by external stimuli[12, 17].

\section{CONCLUSION}

The method of hypogalactia treatment using electrical acupoint effectively increases breast milk volume and improves prolactin content. Paired t-test statistical test has been conducted to differentiate the effects of electrical acupoint treatment on breastfeeding mothers. Results show significant differences $(\mathrm{p}<0$. 05) after implementation of electrical acupoint against breast milk volume and prolactin content. The treatment method in this research involves application of low frequency electrical stimuli to activate meridian line at acupoint points $\mathrm{ST}_{1}, \mathrm{SP}_{6}$ and $\mathrm{ST}_{36}$. The feedback gained from this application provides both local effects and overall hormonal mechanical responses from the body. Local effects increase concentration of Nitride Oxide (NO) and improve the circulation of cyclic monophosphate guanosine (cGMP), as well as opioid and neuropeptide Y. Overall hormonal mechanical responses activate the hypothalamus pituitary adrenal axis that in turn increases cortisol content and modulates the transmittance of endorphin and serotonin to the brain and certain organs via the nerves. The feedback from this anterior hypophysis helps secretes prolactin hormone. Therefore, electrical acupoint has been proven to be capable of treating the problem of hypogalactia.

\section{REFERENCES}

1. Eidelman AI, Schanler RJ, Johnston M, Landers S, Noble L, Szucs K, et al. Breastfeeding and the use of human milk. Pediatrics. (2012);129(3):e827-e41.

2. Temple Newhook J, Newhook LA, Midodzi WK, Murphy Goodridge J, Burrage L, Gill N, et al. Determinants of nonmedically indicated in-hospital supplementation of infants whose birthing parents intended to exclusively breastfeed. Journal of Human Lactation. (2017);33(2):278-84.

3. Maula SN, Widyawati MN, editors. The Effect Of Electric Breast Pump In Increasing Breat Milk Production Proceedings of the International Conference on Applied Science and Health; (2017).

4. Asztalos EV, Campbell-Yeo M, da Silva OP, Ito S, Kiss A, Knoppert D, et al. Enhancing human milk production with domperidone in mothers of preterm infants: results from the Empower trial. Journal of Human Lactation. (2017);33(1):181-7.

5. Esfahani MS, Berenji-Sooghe S, Valiani M, Ehsanpour S. Effect of acupressure on milk volume of breastfeeding mothers referring to selected health care centers in Tehran. Iranian journal of nursing and midwifery research. (2015);20(1):7.

6. Luo D, Wang X, He J. A comparison between acute pressure block of the sciatic nerve and acupressure: methodology, analgesia, and mechanism involved. Journal of pain research. (2013);6:589.

7. Mehta P, Dhapte V, Kadam S, Dhapte V. Contemporary acupressure therapy: Adroit cure for painless recovery of therapeutic ailments. Journal of traditional and complementary medicine. (2017);7(2):251-63.

8. Li K. A Pilot Study to Evaluate the Effect of Acupuncture on Increasing Milk Supply of Lactating Mothers: Victoria University; (2003).

9. Neri I, Allais G, Vaccaro V, Minniti S, Airola G, Schiapparelli $\mathrm{P}$, et al. Acupuncture treatment as breastfeeding support: preliminary data. The Journal of Alternative and Complementary Medicine. (2011);17(2):133-7.

10. Busch D, Silbert-Flagg J. Opioid Use Dependency in the Mother Who Desires to Breastfeed Her Newborn: A Case Study. Journal of Pediatric Health Care. 2018;32(3):223-30.

11. Suryono S, Suseso JE, Mashuri C, Sabila AD, Nugraha JAM, Primasiwi MH. RFID Sensor for Automated Prediction of Reorder Point (ROP) Values in a Vendor Management Inventory (VMI) System Using Fuzzy Time Series. Advanced Science Letters. 2017;23(3):2398-400.

12. Han J-S. Acupuncture: neuropeptide release produced by electrical stimulation of different frequencies. Trends in neurosciences. (2003);26(1):17-22.

13. RJ WK. Breastfeeding and Human Lactation 5th Edition (2016):79-156. 
14. Andrews Z. Neuroendocrine regulation of prolactin secretion during late pregnancy: easing the transition into lactation. Journal of neuroendocrinology. (2005);17(7):466-73.

15. Fu J-Y, Zhang X, Zhao Y-H, Tong H-F, Chen D-Z, Huang $M-H$. Scientific production and citation impact: a bibliometric analysis in acupuncture over three decades. Scientometrics. (2012);93(3):1061-79.
16. Ma S-X. Enhanced nitric oxide concentrations and expression of nitric oxide synthase in acupuncture points/meridians. The Journal of Alternative \& Complementary Medicine. (2003);9(2):207-15.

17. Bellew W. James MLS, Nolan P. Thomas. Modalities for Therapeutic Intervention. 2016:225-315. 